\title{
Bridging with Mechanical Circulatory Support for Cardiac Retransplantation: Analysis of the United Network Organ Sharing Database
}

\section{Erol V Belli* ${ }^{1 *}$ Phillip J Habib ${ }^{2}$, Bhupendra Rawal ${ }^{3}$ and Kevin Landolfo ${ }^{4}$}

${ }^{1}$ Department of Surgery, Mayo Clinic Florida, USA

${ }^{2}$ Department of Cardiology, Mayo Clinic Florida, USA

${ }^{3}$ Department Biostatistics and Bioinformatics, Mayo Clinic Florida, USA

${ }^{4}$ Department of Cardiothoracic Surgery and Transplantation, Mayo Clinic Florida, USA

\begin{abstract}
Background: Cardiac retransplantation ( $\mathrm{ReTx}$ ) remains an infrequent event, and bridging patients with mechanical circulatory support provides another option while patients await suitable donors.

Methods: The United Network for Organ Sharing database was retrospectively reviewed to identify patients undergoing ReTX between 1995-2012. Of the total 28,464 transplants performed during that period, 850 were retransplants and $29(3.4 \%)$ had VAD support prior to retransplant with available data. The primary outcome investigated was overall survival and patients were stratified based on presence of VAD and time between transplant and retransplant (PRVTXDIF). Comparison was undertaken between four groups (G1: ReTX without VAD and PRVTXDIF > 30days, G2: ReTX with VAD and PRVTXDIF <=30days, G3: ReTX with VAD and PRVTXDIF >30 days, G4: ReTX without VAD and PRVTXDIF $<=30$ days). These were tested with univariate logistical regression and multivariate Cox regression models.
\end{abstract}

Results: In multivariable analysis, the relative risk of death for patients in G3 vs $\mathrm{G} 1$ was not statistically significant $(\mathrm{RR}=0.37,95 \% \mathrm{Cl}=(0.1,1.5), \mathrm{P}=0.16)$; and the relative risk of death was 1.7 times higher in $\mathrm{G} 2$ compared to that in $\mathrm{G} 4$, which was not statistically significant $(\mathrm{RR}=1.7,95 \% \mathrm{Cl}=(0.8,4.0), \mathrm{P}=0.20)$. Donor's age $(\mathrm{RR}: 1.1, \mathrm{P}=0.038)$ and ischemic time greater than 4 hours ( $R R: 1.6, P=0.001$ ) were significant predictors of survival.

Conclusion: Cardiac retransplantation may be undertaken safely when patients are maintained on mechanical support and further out from primary transplant.

Keywords: Cardiac retransplantation; Transplantation; Mechanical circulatory support

\section{Introduction}

Ventricular assist devices have been shown to improve survival when compared to medical management over the last decade [1]. Previous studies have shown worse survival with bridging to retransplant when the time between transplant is less than 1 year [2]. However, this particular study included patients over a 24 year period and those bridged with extracorporeal membrane oxygenation, which is known to confer a dismal prognosis [3]. Our study provides a review of ReTX in the United States from 1995-2012 using data submitted to the UNOS database, a prospectively collected registry that collects voluntary data from all United States transplant centers. This analysis focused on evaluation of overall survival following ReTX with particular interest in patients requiring ventricular assist devices and not ECMO support. The interval between transplants in our analysis was also shortened to 30 days and is limited to contemporary cohort of patients who have undergone cardiac ReTX with and without VAD support in the United States from 1995-2012 in order to provide updated information on risk factors and overall survival.

\section{Methods}

\section{Study patients \& data collection}

This was a retrospective review of all 850 patients from The United Network of Organ Sharing database for adult patients who had had heart ReTX between 1995-2012. Information was collected regarding recipient (age at initiation, age at ReTX, gender, citizenship, initial BMI, acute rejection episodes, graft failure cause, days listed as status 1 , days listed as status $1 \mathrm{a}$, days listed as status $1 \mathrm{~b}$, days listed as status 2 , length of hospital stay, serum total albumin, ventricular assist device (VAD) prior to ReTX status, inotropes status, ventilator status, intraaortic balloon pump (IABP) status, extracorporeal membrane oxygenation (ECMO) status, diabetes, dialysis) and information regarding donor (age, gender, and LV ejection fraction of heart). We excluded those patients less than 18 years of age, patients requiring ECMO, and patients with missing data. Variables were submitted to univariate analysis and multivariate analysis.

\section{Statistical analysis}

Continuous variables were summarized with the sample median and range. Categorical variables were summarized with number and percentage. The Kaplan-Meier curve analysis along with log-rank test was used to assess overall survival following ReTX according to status of VAD support and time difference between current ReTX and the previous transplant. Single variable Cox proportional hazards regression models were used to evaluate associations of recipient and donor characteristics with overall survival following retransplantation according to their VAD support status and the time duration between

*Corresponding author: Erol $\mathrm{V}$ Belli, Suregon, Department of Cardiothoracic Surgery, Mayo Clinic Florida, 4500 San Pablo Blvd, Jacksonville, FL 32207, USA Tel: 8137274262; E-mail: belli.erol@mayo.edu

Received August 01, 2014; Accepted October 17, 2014; Published October 21 2014

Citation: Belli EV, Habib PJ, Rawal B, Landolfo K (2014) Bridging with Mechanica Circulatory Support for Cardiac Retransplantation: Analysis of the United Network Organ Sharing Database. J Transplant Technol Res 4: 139. doi:10.4172/21610991.1000139

Copyright: $\odot 2014$ Belli EV, et al. This is an open-access article distributed under the terms of the Creative Commons Attribution License, which permits unrestricted use, distribution, and reproduction in any medium, provided the original author and source are credited. 
current ReTX and the previous transplant; relative risks (RRs) and 95\% confidence intervals (CIs) were estimated. A multivariable Cox proportional hazards regression model was used to assess if any significant association of recipient and donor characteristics would still hold true while controlling for other confounding variables. No adjustment for multiple testing was made in these exploratory analyses, and p-values $\leq 0.05$ were considered as statistically significant. Statistical analysis was performed using SAS (version 9.2; SAS Institute, Inc., Cary, North Carolina) and R Statistical Software (version 2.14.0; R Foundation for Statistical Computing, Vienna, Austria).

\section{Results}

A summary of recipient and donor information is displayed in (Table 1) for the 850 study recipients. Median age of recipients at ReTX was 48 years (Range: 18-74) and median age at ReTX initiation was 47 years (Range: 15-73). Most of the recipients were male (70\%). The median initial BMI of recipient was $26.1 \mathrm{~kg} /$ meter sq. (Range: 12.350.7). The median organ ischemic time was 3.3 hours (Range: 1.0-9.2) and $23 \%$ of the recipients had an ischemic time of more than 4 hours. The majority of the participants $(63 \%)$ had serum total albumin $\leq 3$. Only 29 (3.4\%) recipients had VAD prior to transplant. Forty three patients (5\%) required an intraaortic balloon pump (IABP), 47 (5.5\%) were on ventilator support, and $399(47 \%)$ were on inotropes therapy prior to transplant. Ninety three recipients $(10.9 \%)$ had either type 1 or type 2 diabetes diagnosed prior to transplant and 63 (7.4\%) were using either hemo- or peritoneal dialysis prior to transplant. The median donor age was 29 years (Range: 9-63), and 567 (67\%) donors were male. The majority of the donor hearts (97\%) had left ventricular ejection fraction of $50 \%$ or more and only $20(2.3 \%)$ had left ventricular ejection fraction of $40 \%$ or less.

With a median follow-up length of 3 years (Range: 0 - 17.1 years), a total of 346 patients (40.7\%) died during follow-up. Survival estimates according to $\mathrm{VAD}$ and non-VAD support status and difference of time between previous transplant and current ReTX (PRVTXDIF) is given in (Table 2) and (Figure 1). Associations of survival with recipients and donor characteristics are displayed in (Table 3). Overall survival (OS) was statistically significant in single variable $(\mathrm{P}<0.001)$ and also in multivariable $(\mathrm{P}=0.005)$ analyses when comparing between four groups (G1: ReTX without VAD and PRVTXDIF > 30days, G2: ReTX with VAD and PRVTXDIF <=30days, G3: ReTX with VAD and PRVTXDIF $>30$ days, G4: ReTX without VAD and PRVTXDIF $<=30$ days) of the patients based on VAD support status and the time difference between current ReTX and the previous transplant. In multivariable analysis, the relative risk of death was nearly 3.4 times higher in $\mathrm{G} 2$ vs. $\mathrm{G} 1(\mathrm{RR}=3.4$, 95\% $\mathrm{CI}=(1.6,7.4), \mathrm{P}=0.002)$; the relative risk of death for patients in G3 was only about $37 \%$ of the relative risk of death for patients in G1 , which was not statistically significant $(\mathrm{RR}=0.37,95 \% \mathrm{CI}=(0.1,1.5)$, $\mathrm{P}=0.16$ ); the relative risk of death was nearly 2 times higher in $\mathrm{G} 4$ vs. $\mathrm{G} 1(\mathrm{RR}=1.99,95 \% \mathrm{CI}=(1.0,3.9), \mathrm{P}=0.050)$; and the relative risk of death was 1.7 times higher in G2 compared to that in G4, which was not statistically significant $(\mathrm{RR}=1.7,95 \% \mathrm{CI}=(0.8,4.0), \mathrm{P}=0.20)$ . The other confounding factors that were statistically significant for mortality in multivariable analysis were donor's age (RR: 1.1, $\mathrm{P}=0.038$ ), and ischemic time of more than 4 hours vs. that of 4 or less hours (RR: 1.6, $\mathrm{P}=0.001)$ ).

\section{Discussion}

Progress has been made with cardiac retransplantation since the first report over 30 years ago [4]. Multiple centers have reported their

\begin{tabular}{|c|c|}
\hline Variables & Overall sample $(\mathrm{N}=850)$ \\
\hline Age at re-transplant (years) & $48(18,74)$ \\
\hline Age at initiation (years) & $47(15,73)$ \\
\hline Sex (male) & $597(70.2 \%)$ \\
\hline Initial BMI & $26.1(12.3,50.7)$ \\
\hline \multicolumn{2}{|l|}{ Ischemic time (hours) categorical } \\
\hline Less or 4 hours & $607(77.4 \%)$ \\
\hline More than 4 hours & $177(22.6 \%)$ \\
\hline \multicolumn{2}{|l|}{ Serum total albumin } \\
\hline$\leq 3$ & $353(63.0 \%)$ \\
\hline$>3$ & $207(37.0 \%)$ \\
\hline VAD prior to transplant & $29(3.4 \%)$ \\
\hline Inotropes & $399(46.9 \%)$ \\
\hline Ventilator & $47(5.5 \%)$ \\
\hline IABP & $43(5.1 \%)$ \\
\hline \multicolumn{2}{|l|}{ Diabetes } \\
\hline Type 1 or 2 & $93(10.9 \%)$ \\
\hline \multicolumn{2}{|l|}{ Dialysis at listing } \\
\hline Hemo/peritoneal dialysis & $63(7.4 \%)$ \\
\hline Donor age (years) & $29(9,63)$ \\
\hline Donor sex (male) & $567(66.7 \%)$ \\
\hline \multicolumn{2}{|l|}{$\begin{array}{l}\text { Left ventricular ejection fraction of donor } \\
\text { heart }\end{array}$} \\
\hline$\leq 40 \%$ & $20(2.3 \%)$ \\
\hline$\geq 50 \%$ & $644(97.0 \%)$ \\
\hline \multicolumn{2}{|c|}{$\begin{array}{l}\text { The sample median (range) is given for continuous variables and number } \\
\text { (percent) is given for categorical variables. Information was not available for } \\
\text { the following variables: initial BMI }(n=28) \text {, ischemic time }(n=66) \text {, left ventricular } \\
\text { ejection fraction of donor heart }(n=186) \text {, serum total albumin }(n=290) \text {, diabetes } \\
(n=9) \text {, dialysis at listing }(n=9) \text {. BMI= body-mass index. VAD=ventricular assist } \\
\text { device. IABP=intraaortic balloon pump. }\end{array}$} \\
\hline
\end{tabular}

Table 1: Recipient and donor characteristics.

experiences, most with dismal results [5-8]. More recent reports using the UNOS database have shown that in selected patients, ReTX is a viable option $[3,9]$. Current guidelines suggest patients that have the best overall survival are at least 6 months from initial transplant $[6,10]$. Others have felt this interval should be extended to 1 year from primary transplant [3]. This leaves a group of patients that are not far from primary transplant with limited options for severe graft dysfunction. Caution has been issued with using VAD in this group due to poor prognosis [11,12].

It is this group of patients, with whom we hypothesized could benefit from bridging to ReTX with VADs. Several small case reports have shown successful bridging with VADs in those with perioperative graft failure [13-15]. Khan et al. looked at patients bridged to retransplant with mechanical support in the UNOS database from 1987-2011, but their analysis spanned a long period of time with older devices and included patients on ECMO [2]. We sought to eliminate those on ECMO from our analysis to specifically look at patients with VAD bridging to ReTX in a contemporary era.

By stratifying the patients with intervals $<30$ and $>30$ days between transplant we can separate patients with severe graft dysfunction immediately post-transplant from those with chronic dysfunction. Our analysis showed marked decrease in 3 year overall survival when $<30$ days from primary transplant whether a patient had a VAD in present or not ( $42 \%$ and $27 \%)$, but there was no statistically significant difference between them. The same held true for patients bridged $>30$ days from their primary transplant. They fared better with 3 year overall survival rates of $85 \%$ when bridged with VAD and $70 \%$ when no VAD was present, but this was not statistically significant. This may be inferred to mean patients with failing grafts may be given the opportunity 
Citation: Belli EV, Habib PJ, Rawal B, Landolfo K (2014) Bridging with Mechanical Circulatory Support for Cardiac Retransplantation: Analysis of the United Network Organ Sharing Database. J Transplant Technol Res 4: 139. doi:10.4172/2161-0991.1000139

Page 3 of 4

\begin{tabular}{|c|c|c|c|c|}
\hline $\begin{array}{l}\text { Length of time after } \\
\text { re-transplantation }\end{array}$ & $\begin{array}{l}\text { Proportion of survival, } \% \\
(95 \% \mathrm{Cl}): \text { Re-tx with VAD and } \\
\text { PRVTXDIF }<=30 \text { days }\end{array}$ & $\begin{array}{l}\text { Proportion of survival, } \%(95 \% \mathrm{CI}) \text { : } \\
\text { Re-tx without VAD and PRVTXDIF <= } \\
30 \text { days }\end{array}$ & $\begin{array}{l}\text { Proportion of survival, } \% \\
(95 \% \mathrm{Cl}) \text { : Re-tx with VAD and } \\
\text { PRVTXDIF > } 30 \text { days }\end{array}$ & $\begin{array}{l}\text { Proportion of survival, } \% \\
\text { (95\% Cl): Re-tx without VAD and } \\
\text { PRVTXDIF > } 30 \text { days }\end{array}$ \\
\hline 1 year & $33 \%(16 \%, 68 \%)$ & $56 \%(40 \%, 79 \%)$ & $93 \%(80 \%, 100 \%)$ & $83 \%(81 \%, 86 \%)$ \\
\hline 2 years & $27 \%(12 \%, 62 \%)$ & $52 \%(36 \%, 76 \%)$ & $85 \%(68 \%, 100 \%)$ & $78 \%(75 \%, 81 \%)$ \\
\hline 3 years & $27 \%(12 \%, 62 \%)$ & $42 \%(26 \%, 68 \%)$ & $85 \%(68 \%, 100 \%)$ & $73 \%(70 \%, 76 \%)$ \\
\hline 4 years & $27 \%(12 \%, 62 \%)$ & $36 \%(21 \%, 63 \%)$ & $85 \%(68 \%, 100 \%)$ & $70 \%(66 \%, 73 \%)$ \\
\hline 5 years & $27 \%(12 \%, 62 \%)$ & $36 \%(21 \%, 63 \%)$ & $85 \%(68 \%, 100 \%)$ & $66 \%(62 \%, 70 \%)$ \\
\hline 6 years & $27 \%(12 \%, 62 \%)$ & $36 \%(21 \%, 63 \%)$ & $85 \%(68 \%, 100 \%)$ & $62 \%(58 \%, 66 \%)$ \\
\hline 7 years & $27 \%(12 \%, 62 \%)$ & $36 \%(21 \%, 63 \%)$ & $85 \%(68 \%, 100 \%)$ & $58 \%(54 \%, 62 \%)$ \\
\hline 8 years & $27 \%(12 \%, 62 \%)$ & $36 \%(21 \%, 63 \%)$ & $85 \%(68 \%, 100 \%)$ & $55 \%(50 \%, 59 \%)$ \\
\hline 9 years & $27 \%(12 \%, 62 \%)$ & $36 \%(21 \%, 63 \%)$ & $85 \%(68 \%, 100 \%)$ & $50 \%(46 \%, 55 \%)$ \\
\hline 10 years & $27 \%(12 \%, 62 \%)$ & $36 \%(21 \%, 63 \%)$ & $85 \%(68 \%, 100 \%)$ & $47 \%(43 \%, 52 \%)$ \\
\hline
\end{tabular}

Table 2: Proportion of survival following re-transplantation according to VAD support and non- VAD support.

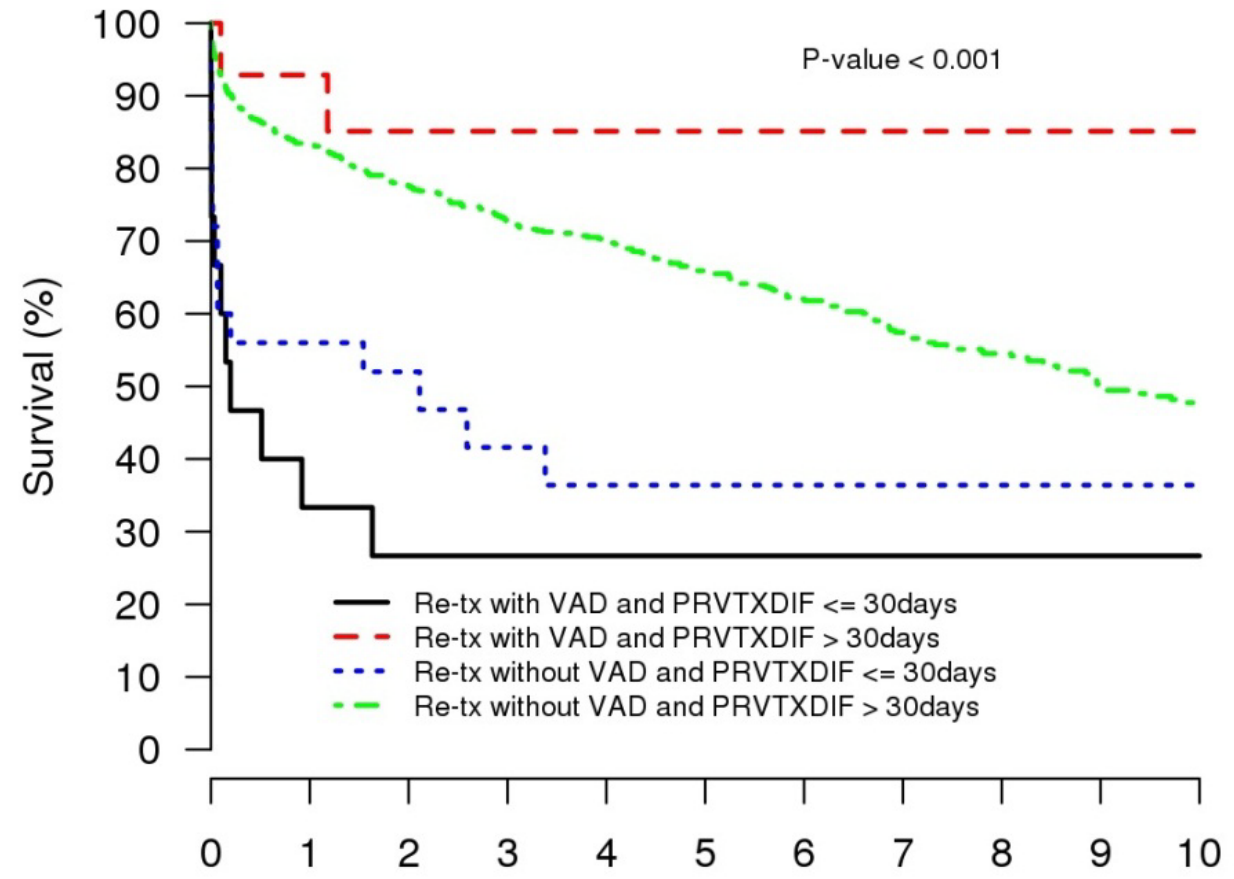

No. at risk

\begin{tabular}{|c|c|c|c|c|c|c|c|c|c|c|c|}
\hline Re-tx with VAD and PRVTXDIF $<=30$ days & 15 & 5 & 4 & 4 & 4 & 4 & 4 & 4 & 4 & 3 & 2 \\
\hline Re-tx with VAD and PRVTXDIF > 30days & 14 & 13 & 11 & 8 & 7 & 7 & 6 & 6 & 6 & 4 & \\
\hline Re-tx without VAD and PRVTXDIF $<=30$ days & 25 & 14 & 10 & 8 & 7 & 6 & 5 & 5 & 5 & 4 & 3 \\
\hline Re-tx without VAD and PRVTXDIF > 30days & 796 & 596 & 495 & 419 & 360 & 310 & 255 & 211 & 169 & 131 & 104 \\
\hline
\end{tabular}

Figure 1: Kaplan-Meier curve of overall survival according to VAD support status and time difference between re-transplant and previous transplant.

for VAD support while awaiting suitable donors with no significant effect on overall survival. This must be interpreted with caution as the authors acknowledge the number of patients included in our study is limited, but it represents the most accurate patient population from the UNOS database in regard to VAD support and retransplantation. The UNOS database is voluntary reported prospective database that may not capture all patients actually bridged to retransplantation, further it contains little information about the VAD device/brand used which is why studies that span long periods of time may include patients with devices no longer in use.
The ideal candidate for retransplantation has been previously reported as a younger patient, whom has a longer interval between ReTX and primary, and receives a younger donor heart with short ischemic time $[3,9]$. Similar results were seen in these study patients who were bridged to retransplant with VAD support. Time $(<30$ days) was a significant factor in overall survival as were donor age and ischemic time. What was not significant may also come as a surprise. The presence of inotropes, ventilator status, dialysis use, and the presence of intraaortic balloon pump were not significant on multivariate analysis. This further adds to the growing body of evidence 
Citation: Belli EV, Habib PJ, Rawal B, Landolfo K (2014) Bridging with Mechanical Circulatory Support for Cardiac Retransplantation: Analysis of the United Network Organ Sharing Database. J Transplant Technol Res 4: 139. doi:10.4172/2161-0991.1000139

Page 4 of 4

\begin{tabular}{|c|c|c|c|c|}
\hline \multirow[b]{2}{*}{ Variable } & \multicolumn{2}{|c|}{ Single variable analysis } & \multicolumn{2}{|c|}{ Multivariable analysis } \\
\hline & $\mathrm{RR}(95 \% \mathrm{Cl})$ & P-value & $\mathrm{RR}(95 \% \mathrm{CI})$ & P-value \\
\hline VAD support status & \multicolumn{2}{|c|}{ Test of overall difference: $\mathrm{P}<0.001$} & \multicolumn{2}{|c|}{ Test of overall difference: $P=0.005$} \\
\hline Re-tx without VAD and PRVTXDIF > 30days & 1.00 (reference) & $\mathrm{N} / \mathrm{A}$ & 1.00 (reference) & $\mathrm{N} / \mathrm{A}$ \\
\hline Re-tx with VAD and PRVTXDIF <= 30days & $2.75(1.51,5.02)$ & 0.001 & $3.42(1.58,7.44)$ & 0.002 \\
\hline Re-tx with VAD and PRVTXDIF $>30$ days & $0.31(0.08,1.25)$ & 0.10 & $0.37(0.09,1.50)$ & 0.16 \\
\hline Re-tx without VAD and PRVTXDIF $<=30$ days & $1.99(1.18,3.34)$ & 0.009 & $1.99(1.00,3.94)$ & 0.050 \\
\hline $\begin{array}{l}\text { Re-tx with VAD and PRVTXDIF }<=30 \text { days vs. } \\
\text { Re-tx without VAD and PRVTXDIF }<=30 \text { days ( reference) }\end{array}$ & $1.38(0.63,3.01)$ & 0.42 & $1.73(0.75,3.99)$ & 0.20 \\
\hline Age at re-transplant (10 year increase) & $1.08(1.00,1.16)$ & 0.053 & $1.08(0.99,1.17)$ & 0.078 \\
\hline Gender (male) & $0.84(0.67,1.05)$ & 0.13 & $\mathrm{NI}$ & $\mathrm{N} / \mathrm{A}$ \\
\hline Donor age (10 year increase) & $1.13(1.04,1.23)$ & 0.004 & $1.10(1.01,1.21)$ & 0.038 \\
\hline Ischemic time (> 4 hours) & $1.53(1.19,1.97)$ & 0.001 & $1.59(1.22,2.06)$ & 0.001 \\
\hline Serum total albumin $(>3)$ & $0.67(0.49,0.91)$ & 0.010 & $\mathrm{NI}$ & N/A \\
\hline Inotropes & $1.16(0.94,1.44)$ & 0.16 & $\mathrm{NI}$ & $\mathrm{N} / \mathrm{A}$ \\
\hline Ventilator & $1.82(1.23,2.69)$ & 0.003 & $1.02(0.55,1.87)$ & 0.96 \\
\hline IABP & $1.54(1.01,2.35)$ & 0.047 & $1.21(0.74,1.97)$ & 0.44 \\
\hline Diabetes & $1.18(0.92,1.51)$ & 0.18 & $\mathrm{NI}$ & $\mathrm{N} / \mathrm{A}$ \\
\hline Dialysis at listing & $1.34(0.98,1.84)$ & 0.068 & $1.40(0.95,2.06)$ & 0.089 \\
\hline
\end{tabular}

Relative risks, 95\% confidence intervals, and p-values result from Cox proportional hazards regression models. Relative risks correspond to presence of the given characteristic (categorical variables) or the increase given in parenthesis (continuous variables). All variables with $p$-value $\leq 0.10$ in a single variable analysis were included in multivariable analysis (\# used= 776) except serum total albumin because of the large number of missing information (\# missing $=290)$ with this variable. $\mathrm{IABP}=$ intraaortic balloon pump. $\mathrm{RR}=$ relative risk. $\mathrm{Cl}=$ confidence interval. $\mathrm{NI}=$ not included in the multivariable analysis. $\mathrm{N} / \mathrm{A}=$ not applicable. $\mathrm{PRVTXDIF=}$ time difference between re-transplant and previous transplant.

Table 3: Associations of recipient and donor characteristics with overall survival following re-transplant.

that ReTX can be undertaken in patients with no statistical difference in overall survival even whena patient must be supported with a VAD.

\section{Acknowledgment}

"This work was supported in part by Health Resources and Services Administration contract 234-2005-37011C. The content is the responsibility of the authors alone and does not necessarily reflect the views or policies of the Department of Health and Human Services, nor does mention of trade names, commercial products, or organizations imply endorsement by the U.S. Government".

\section{References}

1. Dembitsky WP, Tector AJ, Park S, Moskowitz AJ, Gelijns AC, et al. (2004) Left ventricular assist device performance with long-term circulatory support: lessons from the REMATCH trial. Ann Thorac Surg 78: 2123-2129.

2. Khan MS, Mery CM, Zafar F, Adachi I, Heinle JS, et al. (2012) Is mechanically bridging patients with a failing cardiac graft to retransplantation an effective therapy? Analysis of the United Network of Organ Sharing database. J Heart Lung Transplant 31: 1192-1198.

3. Belli E, Leoni Moreno JC, Hosenpud J, Rhawal B, Landolfo K (2014) Preoperative risk factors predict survival following cardiac retransplantation Analysis of the United Network for Organ Sharing database. J Thorac Cardiovasc Surg 147: 1972-1977.

4. Copeland JG, Griepp RB, Bieber CP, Billingham M, Schroeder JS, et al. (1977) Successful retransplantation of the human heart. J Thorac Cardiovasc Surg 73: $242-247$

5. Chou NK, Chi NH, Chen YS, Yu HY, Lee CM, et al. (2006) Heart retransplantation for heart allograft failure in Chinese heart transplant recipients: NTUH experience. Transplant Proc 38: 2147-2148.

6. Karwande SV, Ensley RD, Renlund DG, Gay WA Jr, Richenbacher WE, et al. (1992) Cardiac retransplantation: a viable option? The Registry of the International Society for Heart and Lung Transplantation. Ann Thorac Surg 54: 840-844.
7. Schlechta B, Kocher AA, Ehrlich M, Ankersmit J, Ploner M, et al. (2001) Heart retransplantation: institutional results of a series of 31 cases. Transplant Proc 33: $2759-2761$.

8. Smith JA, Ribakove GH, Hunt SA, Miller J, Stinson EB, et al. (1995) Heart retransplantation: the 25-year experience at a single institution. J Heart Lung Transplant 14: 832-839.

9. Srivastava R, Keck BM, Bennett LE, Hosenpud JD (2000) The results of cardiac retransplantation: an analysis of the Joint International Society for Heart and Lung Transplantation/United Network for Organ Sharing Thoracic Registry. Transplantation 70: 606-612.

10. Johnson MR, Aaronson KD, Canter CE, Kirklin JK, Mancini DM, et al. (2007) Heart retransplantation. Am J Transplant 7: 2075-2081.

11. Ibrahim M, Hendry P, Masters R, Rubens F, Lam BK, et al. (2007) Management of acute severe perioperative failure of cardiac allografts: a single-centre experience with a review of the literature. Can J Cardiol 23: 363-367.

12. Noirhomme P, d'Udekem Y, Jacquet L, El Khoury G, Verhelst R, et al. (1997) Is mechanical circulatory support helpful before cardiac retransplantation? Cardiovasc Surg 5: 584-587.

13. Ricci M, Panos AL, Andreopoulos FM, Rusconi P, Rosenkranz E, et al. (2009) Successful use of a custom-made paracorporeal total artificial heart as a bridge to retransplantation in adult and adolescent patients. J Heart Lung Transplant 28: 834-837.

14. Samoukovic G, Al-Atassi T, Rosu C, Giannetti N, Cecere R (2009) Successfu treatment of heart failure due to acute transplant rejection with the Impella LP 5.0. Ann Thorac Surg 88: 271-273.

15. Thomas HL, Dronavalli VB, Parameshwar J, Bonser RS, Banner NR (2011) Incidence and outcome of Levitronix CentriMag support as rescue therapy for early cardiac allograft failure: a United Kingdom national study. Eur J Cardiothorac Surg 40: 1348-1354 